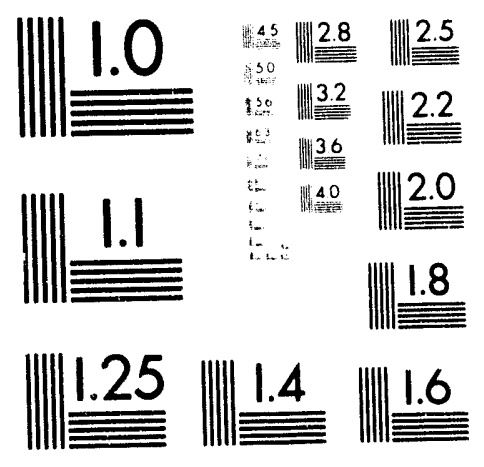



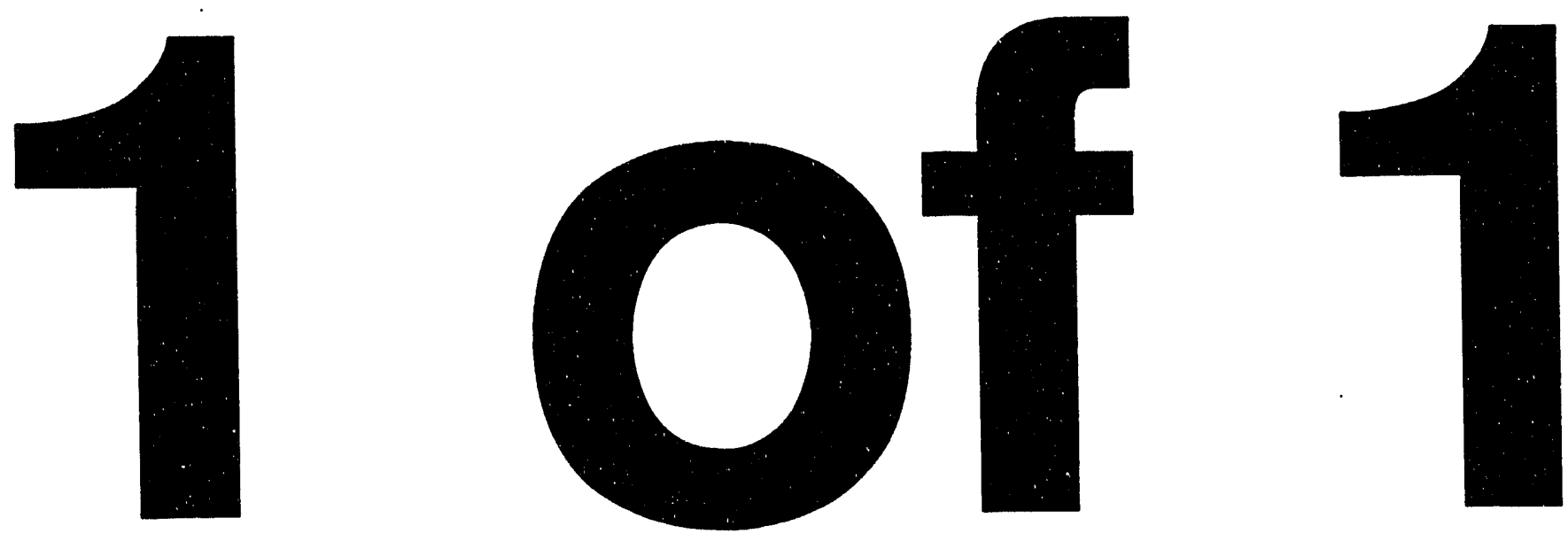


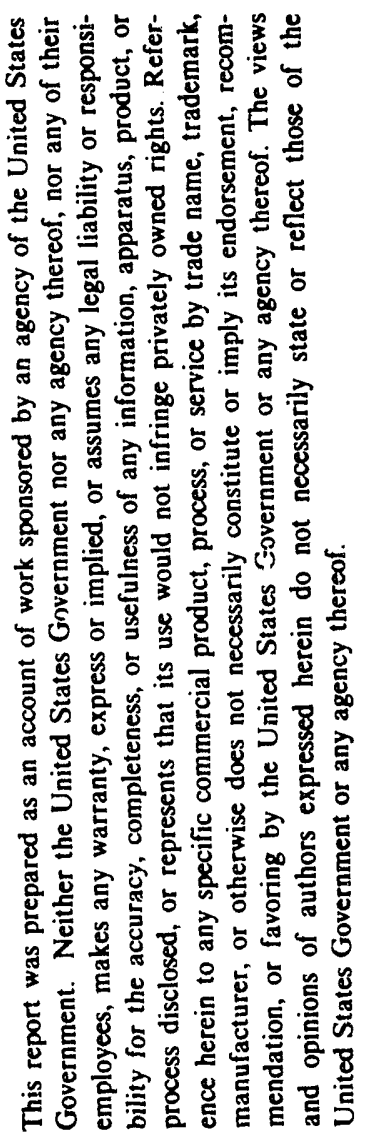

Submitted to:

Darryl P. Butt

Richard E. Tressler

Karl E. Spear

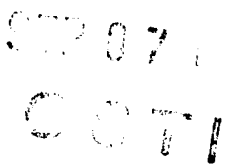

Author(s):

DISCONTINUOUS PHASE FORMATION AND SELECTIVE ATTACK OF SIC MATERIALS EXPOSED TO LOW OXYGEN PARTIAL PRESSURE ENVIRONMENTS

NATO ADVANCED RESEARCH WORKSHOP

CORROSION OF ADVANCED CERAMICS

\section{MASTER}

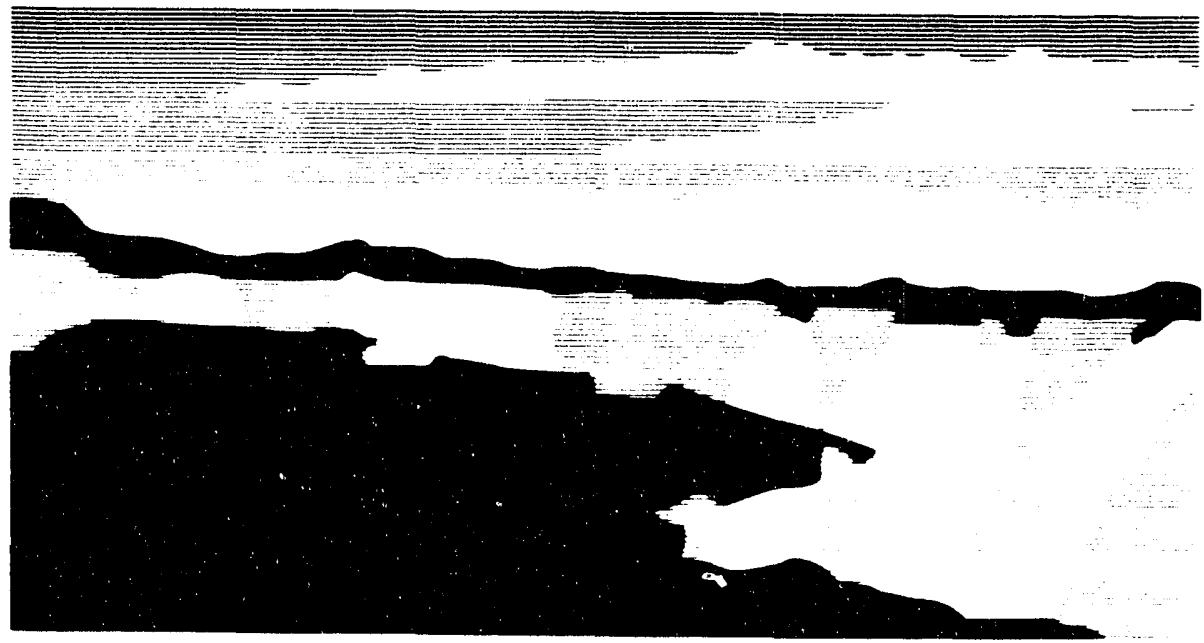

NATIONAL LABORATORY

Los Alamos National Laboratory, an aftirmative action/equal opportunity employer, is operated by the University of California for the U.S. Department of Energy under contract W.7405-ENG-36. By acceptance of this anticle. the publisher recognizes that the U.S. Government retains a nonexclusive, royalty-free license to publish or reproduce the published form of this contribution, or to allow others to do so, for U.S. Government purposes. The Los Alamos Nationi' Laboratory requests that the publisher identity this article as work performed under the auspices of the U.S. Department of Energy. 


\title{
DISCONTINUOUS PHASE FORMATION AND SELECTIVE ATTACK OF SiC MATERIALS EXPOSED TO LOW OXYGEN PARTIAL PRESSURE ENVIRONMENTS
}

\author{
Darryl P. Butt,* Richard E. Tressler** and Karl E. Spear** \\ * Nuclear Materials Technology and \\ Materials Science Technology Divisions, \\ P.O. Box 1663, M.S. E505 \\ Los Alamos National Laboratory \\ Los Alamos, NM 87545 USA \\ **Department of Materials Science and Engineering \\ 101 Steidle Building \\ The Pennsylvania State University \\ University Park, PA 16802 USA
}

\begin{abstract}
Three $\mathrm{SiC}$ materials were exposed to gas mixtures containing $\mathrm{N}_{2}, \mathrm{H}_{2}$, and $\mathrm{CO}$ at $1000-1300^{\circ} \mathrm{C}, 1-740$ torr for a few to $1000 \mathrm{~h}$. Kinetic and thermodynamic studies indicate that $\mathrm{CO}$ is the predominant oxidizing species. A variety of corrosion processes were observed, including surface and internal pit formation, needle growth, grain boundary attack, and attack of impurities and surrounding material. In the case of a siliconized SiC, impurities such as $\mathrm{Ca}, \mathrm{Al}$, and $\mathrm{Fe}$ diffused rapidly through the Si matrix forming complex calcium aluminosilicates on the surface, leaving behind internal voids. Evaluation of the mechanical properties, including fractography, revealed a variety of degradative phenomena. Efforts to identify causes of pit formation suggested that the overall process was complex. Pits formed during attack of grain boundaries and regions containing transition metal impurities. Studies of single crystals showed preferential attack near impurities and crystalline defects, indicating that damaged crystals or certain crystal orientations in the polycrystalline materials are susceptible to attack. In addition, under some conditions where pit formation was observed, the strength of certain materials increased apparently due to flaw healing. It is suggested that flaws can heal in the absence of mechanical stress due to their high surface energy. However, second phases observed within partially healed surface cracks suggest impurities also contribute to the flaw healing processes.
\end{abstract}

\section{Introduction}

Silicon Carbide materials are candidates for a variety of high-temperature combustion applications. This study was initiated out of concern for the durability of SiC materials in low $\mathrm{pO}_{2}$ metallurgical heat treatment environments. Typically, Si-based ceramics are not considered for use in low $\mathrm{pO}_{2}$ atmospheres where active oxidation may occur. However, recently the heat treatment industry has begun using $\mathrm{SiC}$ radiant tubes in indirect gas-fired heat treating operations. In such systems, the tubes are internally heated by combustion bumers and radiate heat to some external work load, such as an ingot of alloy, which is isolated from the combustion atmosphere. The heat treatment atmospheres, which surround the outer surface of the radiant tube, are frequently comprised of $\mathrm{N}_{2}, \mathrm{H}_{2}$, and $\mathrm{CO}$ often with significant percentages of $\mathrm{CH}_{4}, \mathrm{CO}_{2}$, and $\mathrm{H}_{2} \mathrm{O}$. For a review of heat treatment environments the reader is referred to a review by the ASM Committee on Furnace Atmospheres. ${ }^{1}$

Jacobson ${ }^{2}$ has suggested that in combustion environments there are five main mechanisms of corrosive degradation any of which may operate simultaneously: passive oxidation, deposit-induced corrosion, active oxidation, scale/substrate interactions, and scale volatility. Of course, the engineer or furnace operator of a combustion system is primarily concerned with the effects that these phenomena have on the useful life of his materials. Uniform corrosion is not particularly deleterious in that the primary degradation mechanism is the 
gradual loss of component dimensions or cross-section and, therefore, loss of load-bearing capacity. Selective attack, such as pitting, is of great concern since it can result in a significant reduction in component strength with only a small amount of material loss.

In previous publications ${ }^{3-6}$ we described the thermodynamics and kinetics of reactions, and the effects on mechanical properties, of $\mathrm{SiC}$ materials exposed to $\mathrm{N}_{2}-\mathrm{H}_{2}-\mathrm{CO}$ heat treatment environments. In this paper we discuss certain interesting aspects of the observed heterogencous reactions that were not previously covered in detail in an effort to foster discussion in this relatively unexplored area of ceramics corrosion research. The emphasis of the discussion is on those processes, and their kinetics, which lead to a loss of strength.

\section{Experimental Procedures}

Two heat treatment gases were used in these studies, an endothermic gas and a nitrogenbased gas. The calculated equilibrium compositions of both gases at $1300^{\circ} \mathrm{C}$ are summarized in table 1. These atmospheres were selected because they represent opposite ends of the compositional spectrum of industrial heat treatment gases. Studies were done at 1000 to $1350^{\circ} \mathrm{C}$ at $1-740$ torr for up to $1000 \mathrm{~h}$. As described in table 1 , three SiC materials were used in these studies, a B-doped sintered SiC (Hexoloy SA, Carborundum Co., Niagara Falls, NY), an Al-doped sintered SiC (Elektroschmelzwerk Kempten GmbH, FRG), and a siliconized SiC (SCRB210, Coors Ceramics Co., Golden, CO).

Table 1. Physical properties data for the experimental SiC materials.

\begin{tabular}{lccc} 
Property/Analysis & Siliconized $\mathrm{SiC}^{*}$ & $\frac{\text { B-Doped } \mathrm{SiC}}{3.16}$ & $\frac{\text { Al-Doped SiC }}{3.14}$ \\
\cline { 2 - 3 } Density, g/cc & 3.05 & 0 & $<3$ \\
\% Porosity & 0 & $<2$ & \\
SiC Grain Size, $\mu \mathrm{m}$ & $2-5$ and $25-75$ & $2-8$ & $2-5$ and $80-200^{* *}$ \\
Major Impurities $(0.5-2 \%)$ & $\mathrm{Al}, \mathrm{Fe}, \mathrm{Ca}$ & $\mathrm{B}$ & $\mathrm{Al}$ \\
Minor Impuritics $(0.01-0.49 \%)$ & $\mathrm{Mg}, \mathrm{Ti}, \mathrm{V}, \mathrm{Cr}$, & $\mathrm{Fe}, \mathrm{Mg}, \mathrm{Al}, \mathrm{Ca}$, & $\mathrm{Ti}, \mathrm{Ni}, \mathrm{Fe}, \mathrm{V}$ \\
& $\mathrm{Ni}, \mathrm{Zr}$ & $\mathrm{Cr}$ & $\mathrm{Ca}, \mathrm{Mg}, \mathrm{Zr}$ \\
\hline
\end{tabular}

* The siliconized SiC contained $19 \%$ free silicon by volum

**The large grains were platelets of $\mathrm{SiC}$ and comprised $<10 \%$ of the composition by volume.

Table 2. Calculated $1300^{\circ} \mathrm{C}$ thermodynamic equilibrium of gaseous species in the experimental heat treatment atmospheres.

\begin{tabular}{|c|c|c|}
\hline \multirow[b]{2}{*}{ Component } & \multicolumn{2}{|c|}{- Volume Fraction in Gas- } \\
\hline & Nitrogen-Based & Endothermic* \\
\hline $\mathrm{N}_{2}$ & 0.982 & 0.378 \\
\hline $\mathrm{H}_{2}$ & $1.2 \times 10^{-2}$ & 0.411 \\
\hline $\mathrm{CO}$ & $6.0 \times 10^{-3}$ & 0.211 \\
\hline $\mathrm{CO}_{2}$ & $6.0 \times 10^{-7}$ & $1.6 \times 10^{-5}$ \\
\hline $\mathrm{CH}_{4}$ & $5.5 \times 10^{-9}$ & $2.9 \times 10^{-4}$ \\
\hline $\mathrm{H}_{2} \mathrm{O}$ & $9.0 \times 10^{-5}$ & $3.5 \times 10^{-6}$ \\
\hline $\mathrm{O}_{2}$ & $1.9 \times 10^{-18}$ & $1.1 \times 10^{-18}$ \\
\hline
\end{tabular}

* Solid carbon is predicted to deposit out of the endothermic atmospherc.

The broad experimental approach to this corrosion problem involved correlating the thermodynamics and kinetics of reactions with changes in mechanical properties. The thermodynamics of reactions were modeled using the program SOLGASMIX ${ }^{6}$ and thermodynamic data from the JANAF tables ${ }^{7,8}$ and other sources. ${ }^{9-11}$ The kinetics of 
reactions were studied using thermogravimetric techniques (TGA) and by exposing specimens to the heat treatment atmospheres for long durations in a large vacuum fumace and measuring the resulting weight changes. Corroded specimens were then fractured at room temperature or $1300^{\circ} \mathrm{C}$ in argon. Fractography and microstructural characterization techniques were used to correlate changes in strength with changes in flaw populations. The strength studies described in this paper were done by fracturing $25.4 \times 3.6 \times 3.2 \mathrm{~mm}$ bars at room temperature using a 4-point bend configuration.

\section{Thermodynamics of Reactions Between $\mathrm{SiC}$ Materials and $\mathrm{N}_{2}-\mathrm{H}_{2}$-CO Gases}

Thermodynamic calculations are presented as plots of concentration of product species versus total system pressure at $1300^{\circ} \mathrm{C}$. Figures 1 and 2 show plots of the calculated compositions when excess $\mathrm{SiC}$ is reacted with the nitrogen-based and endothermic gases, respectively. By having a large solid/gas ratio the calculated partial pressures represent the equilibrium partial pressures above the solid. These figures represent the static equilibrium between the respective solid phase and the input gases and are not meant to depict boundary layer effects that can occur in a flowing gas environment. Calculations which do simulate a flowing gas environment have been reported elsewhere. ${ }^{3.6}$

In the case of the nitrogen-based gas (figure 1), the following net etching reaction between the gas and $\mathrm{SiC}$ is predicted to be important at the experimentally used pressures, based on the magnitudes of the calculated partial pressures:

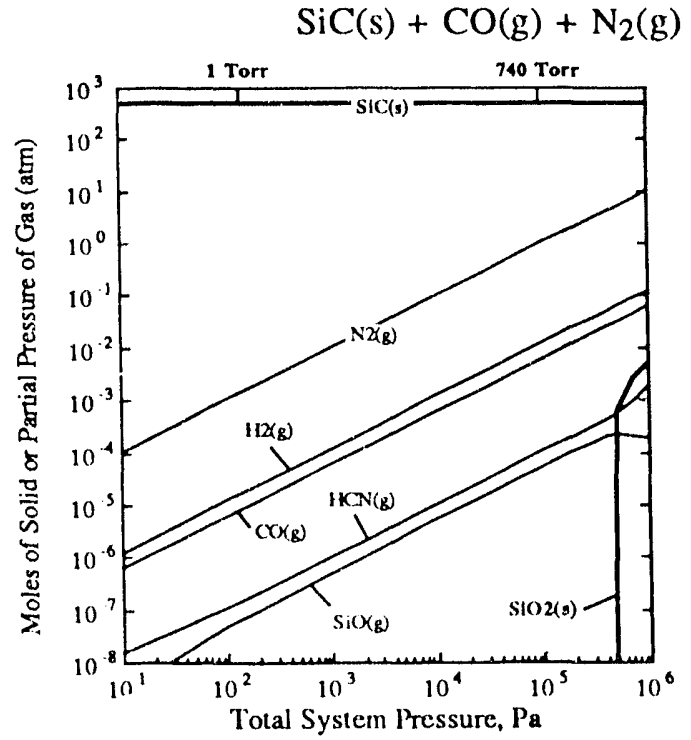

Figure 1. Calculated composition when excess $\mathrm{SiC}$ is reacted with the nitrogen-based gas at $1300^{\circ} \mathrm{C}$, shown as a function of total system pressure.

In the case of the endothermic gas, at $133 \mathrm{~Pa}$ total pressure (figure 2), $\mathrm{SiO}$ is predicted to form along with solid carbon according to the reaction:

$$
\mathrm{SiC}(\mathrm{s})+\mathrm{CO}(\mathrm{g}) \rightarrow \mathrm{SiO}(\mathrm{g})+2 \mathrm{C}(\mathrm{s})
$$

In addition to reaction 2 , at the higher pressure of $98.7 \mathrm{kPa}$, silica is predicted to form when the endothermic gas is in thermodynamic equilibrium with $\mathrm{SiC}$ according to the reaction: 


$$
\mathrm{SiC}(\mathrm{s})+2 \mathrm{CO}(\mathrm{g}) \rightarrow \mathrm{SiO}_{2}(\mathrm{~s})+3 \mathrm{C}(\mathrm{s})
$$

The actual transition pressure above which silica was predicted to become thermodynamically stable is $\approx 40 \mathrm{kPa}$. Note that $\mathrm{HCN}$ is not predicted to be a product of reactions between $\mathrm{SiC}$ and the endothermic gas as was the case for the nitrogen-based gas. Rather, the levels of $\mathrm{HCN}$ shown in figure 2 correspond to the equilibrium partial pressures in the endothermic gas itself.

As discussed elsewhere, 3,6 similar thermodynamic calculations were done for reactions between silicon and the heat treatment gases. It was found that the partial pressures of the product gases $\mathrm{SiO}$ and $\mathrm{Si}$ are orders of magnitude higher above $\mathrm{Si}$ than above $\mathrm{SiC}$ in both heat treatment gases, indicating that volatilization of species from solid Si should be more rapid than from $\mathrm{SiC}$. At $133 \mathrm{~Pa}$ the following net reaction was predicted to be important in both gases, based on the calculated magnitudes of the product partial pressures:

$$
2 \mathrm{Si}(\mathrm{s})+\mathrm{CO}(\mathrm{g}) \rightarrow \mathrm{SiC}(\mathrm{s})+\mathrm{SiO}(\mathrm{g})
$$

Reaction 4 is an etching reaction in that there is a loss of solid phase of $16.07 \mathrm{amu}$ per reaction. At the higher total pressure of $98.7 \mathrm{kPa}$, the following reaction was also predicted to be important:

$$
3 \mathrm{Si}(\mathrm{s})+2 \mathrm{CO}(\mathrm{g}) \rightarrow \mathrm{SiO}_{2}(\mathrm{~s})+2 \mathrm{SiC}(\mathrm{s})
$$

The transition pressures above which silica was predicted to become thermodynamically stable in the nitrogen-based and endothermic gases were $\approx 40$ and $1 \mathrm{kPa}$, respectively.

\section{Kinetics of Corrosion of $\mathrm{SiC}$ Materials in $\mathrm{N}_{2}-\mathrm{H}_{2}-\mathrm{CO}$ Gases}

\subsection{CORROSION OF THE SILICONIZED SiC MATERIAL}

The kinetics of corrosion of the siliconized $\mathrm{SiC}^{\prime}$ were generally complex owing to its two phase microstructure and relatively high impurity content (table 1). Figures 5 and 6 show TGA weight change measurements made during exposures to the nitrogen-based and endothermic gases at 1 torr total pressure. Note, as discussed in detail elsewhere, 3,6 in the endothermic gas (figure 6) there was significant deposition of carbon and silica on the upper portions of the hangdown assembly which was subtracted from the observed TGA profiles. The siliconized $\mathrm{SiC}$ experienced etching in both atmospheres, apparently by reaction (4). The rapid initial weight loss was due to the rapid removal of Si phase as shown in figures 7 and 8.

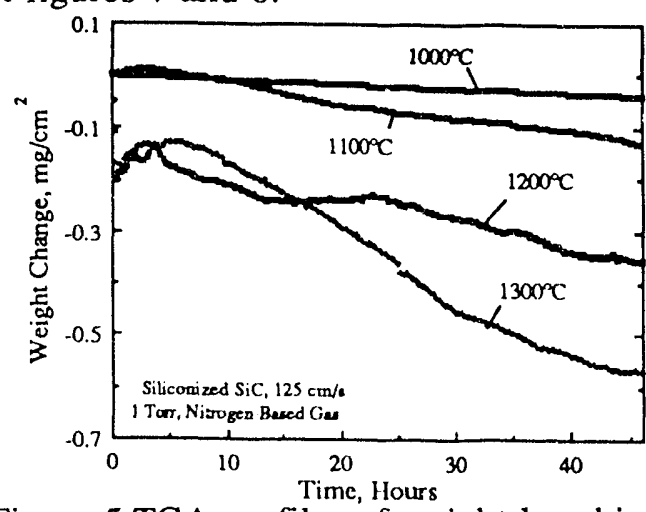

Figure 5.TGA profiles of weight loss kinetics of the siliconized $\mathrm{SiC}$ exposed to the nitrogenbased gas at 1 torr total pressure.

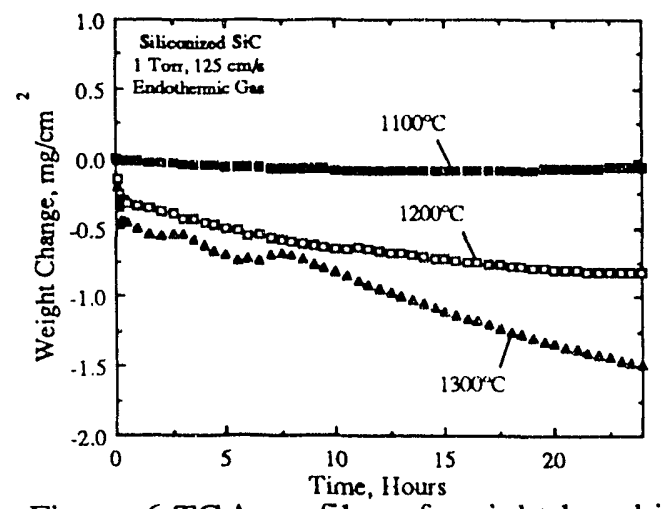

Figure 6.TGA profiles of weight loss kinetics of the siliconized $\mathrm{SiC}$ exposed to the endothermic gas at 1 torr total pressure. 
The complex, non-linear weight loss behavior of the siliconized SiC (figures 5 and 6) was associated with a number of factors: - As the silicon phase is removed the area fraction of $\mathrm{Si}$ directly exposed to the atmosphere decreases. - Once most of the Si has been removed from the surface (to $\approx 100 \mu \mathrm{m}$ ), further removal requires gaseous diffusion through surface porosity. - At long times, when the activity of Si at the surface is sufficiently low, the corrosion rate is determined by the rate of removal of $\mathrm{SiC}$ phase. - And, despite the rapid etching, a significant population of discontinuous phases formed on the surface and in porosity near the surface (see brief periods of weight gain in figures 5 and 6 ).

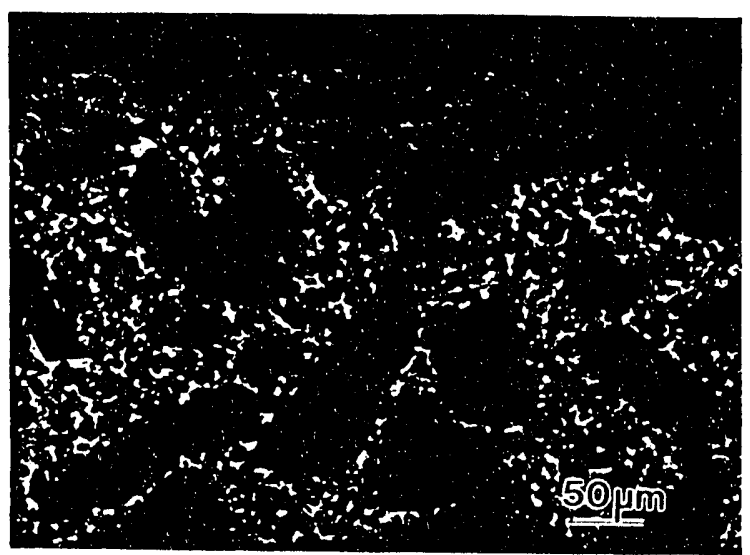

Figure 7. Optical micrograph of a polished cross-section of the siliconized $\mathrm{SiC}$ following exposure to the nitrogen-based gas at $1300^{\circ} \mathrm{C}$, 1 torr for $8 \mathrm{~h}$. (Dark regions $=\mathrm{SiC}$, light regions $=\mathrm{Si}$.)

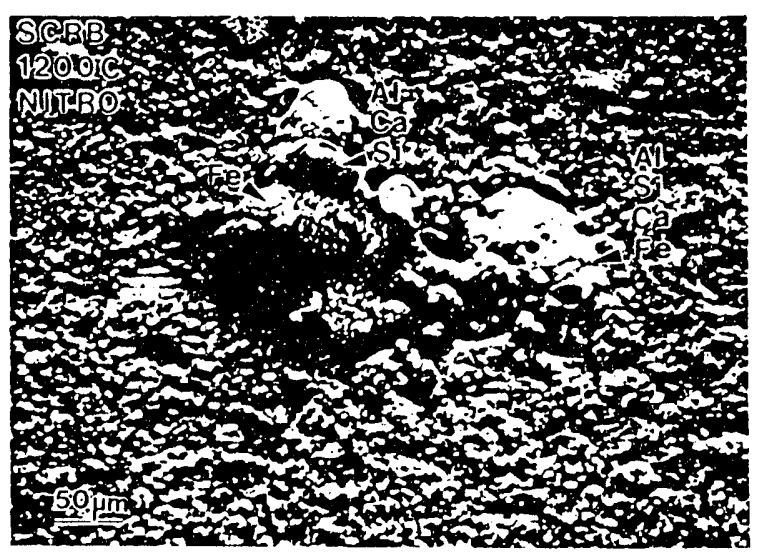

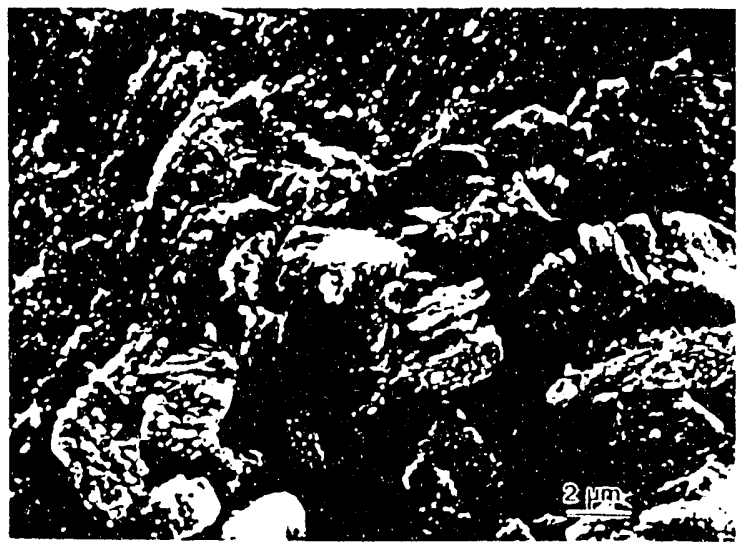

Figure 8. SEM micrograph of the surface morphology of the siliconized SiC followexposure to the nitrogen-based gas at $1300^{\circ} \mathrm{C}, 1$ torr for $150 \mathrm{~h}$. (Note the etching of individual $\mathrm{SiC}$ grains.

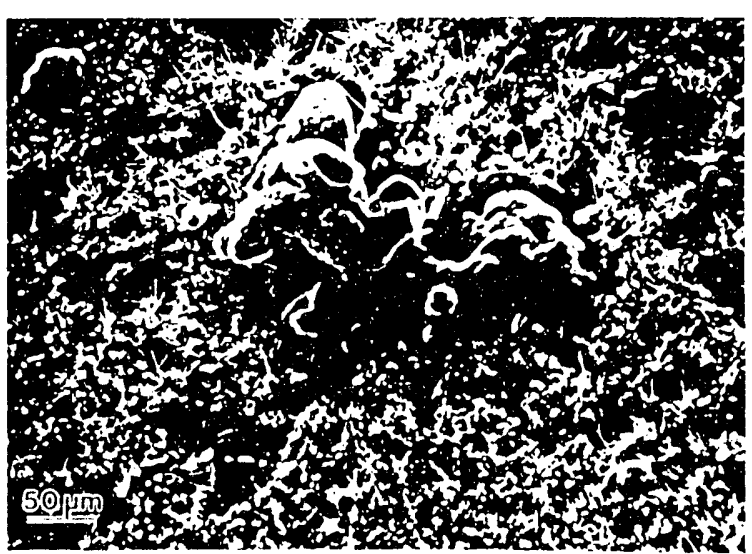

Figure 9. Back scattered (left) and secondary (right) electron micrographs of a large aluminosilicate nodule and silicate whiskers that formed on the surface of the siliconized SiC during exposure to the nitrogen-based gas at $1300^{\circ} \mathrm{C}, 740$ torr for $100 \mathrm{~h}$.

Impurity sinks contained throughout the $\mathrm{Si}$ matrix were the sources of most of the discontinuous phases that formed during corrosion. TEM and SEM/EDX studies 6 demonstrated that the silicon phase contained significant percentages of locally concentrated $\mathrm{Ca}, \mathrm{Al}$, and $\mathrm{Fe}$. Iron and $\mathrm{Si}$ form a eutectic at $1207^{\circ} \mathrm{C} .{ }^{13}$ It was observed that at temperatures above $\approx 1200^{\circ} \mathrm{C}, \mathrm{Fc}, \mathrm{Ca}$, and Al casily diffused to the surface via channels of 
liquid phase. Once at the surface, complex calcium aluminosilicates, such as anorthite and gehlenite, formed due to their high negative free energy of formation (sec figure 9). To further illustrate the mechanism of nodule formation, figure 10 shows a specimen that failed at a large Si inclusion (sce arrows) above which a calcium aluminosilicate nodule has formed. Figure 11 shows a cross-section through a specimen on which a large nodule had grown. The light colored, mushroom-shaped region in the middle of the specimen is a silicon inclusion. The void near the bottom of the inclusion was an impurity sink from which the impurities migrated to the surface through a channel of liquid.

Thus, the complex reaction kinetics of the siliconized $\mathrm{SiC}$ (figures 5 and 6) were primarily associated with the simultancous etching of the Si matrix and formation of discontinuous phases on the surface. Etching of Si occured nonlinearly as the Si/gas interface moves away from the specimen surface. The formation of discontinuous phases occurs in small bursts (as suggested by the short periods of weight gain) as pockets of liquid impurities periodically escape to the surface.

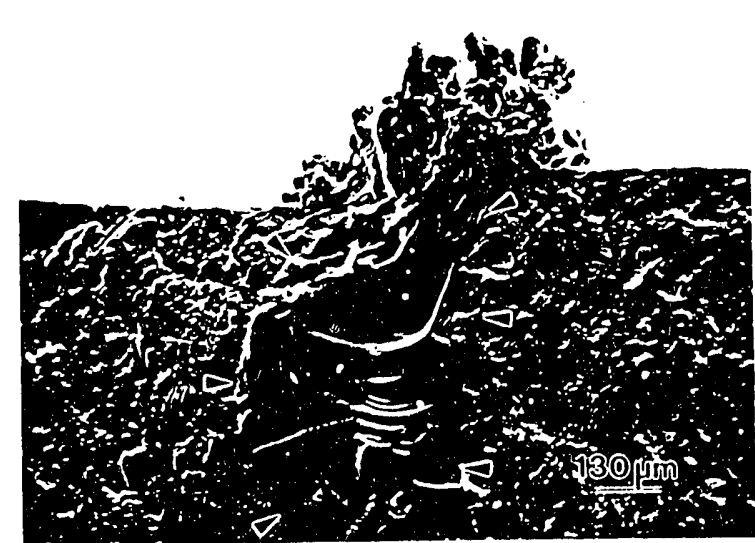

Figure 10. Failure origin $(98 \mathrm{MPa})$ in the siliconized $\mathrm{SiC}$ originating from a large $\mathrm{Si}$ inclusion above which a calcium aluminosilicate nodule has formed $\left(1200^{\circ} \mathrm{C}, 1\right.$ torr, $100 \mathrm{~h}$, nitrogen-based gas).

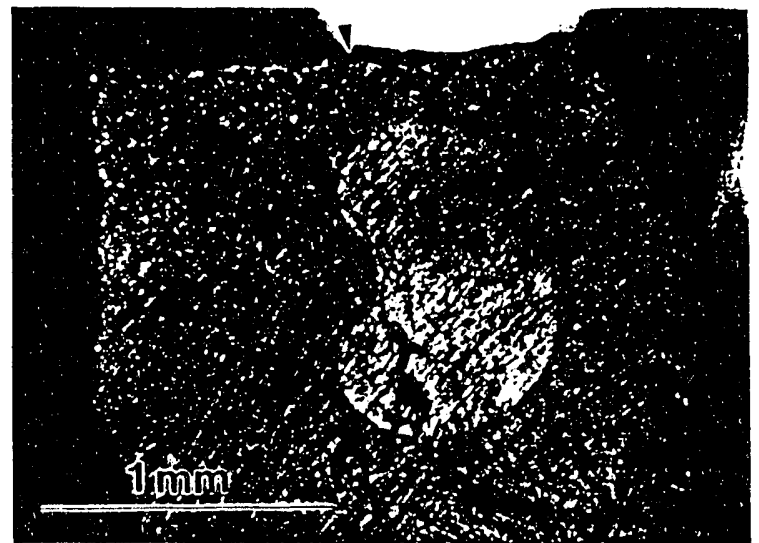

Figure 11. Optical micrograph of a Silicon inclusion from which impurities have migrated through a channel of liquid. The arrow shows the location of a nodule lost during post-mortem sample preparation.

\subsection{CORROSION OF THE SINTERED SiC MATERIALS}

The corrosion of the sintered SiC materials was not as complex as that of the siliconized material due the their more homogenous makeup. For example, in the nitrogen-based gas at 1 torr, the sintered matcrials experienced relatively linear etching (figure 12), apparently due to reaction $(1)$, at times less than $\approx 100 \mathrm{~h} .3,6$ However, longer term exposures revealed that all threc materials actually exhibit non-linear behavior. Figure 13 compares the corrosion rates of all three materials exposed to the nitrogen-based gas for times up to 1000$)$ $\mathrm{h}$. Between 0 and $\approx 300 \mathrm{~h}$ the Al-doped and B-doped SiC materials exhibited nearly identical rates of weight change (as was observed in all the environments studied). However, between 300 and $1000 \mathrm{~h}$ of exposure the Al-doped material was etched at a significantly slower rate than the $\mathrm{B}$-doped $\mathrm{SiC}$. X-ray photoclectron spectroscopy and secondary ion mass spectroscopy 6 indicated that the surface of the Al-doped SiC was comprised of a thin (on the order of $10 \AA$ ) layer of discontinuous $A \mathrm{AN}_{\mathrm{x}}$ and/or $\mathrm{AlO}_{\mathrm{x}} \mathrm{N}_{\mathrm{y}}$ phase, which apparently provided some protection. In the case of the B-doped $\mathrm{SiC}$, no such phases were identified. It is interesting to note that, although the siliconized SiC experienced significantly more etching than the sintered materials, the B-doped SiC and siliconized SiC were etched at nearly identical rates between 300 and $1000 \mathrm{~h}$, suggesting that at long exposure times the rate of corrosion of the siliconized $\mathrm{SiC}$ is controlled by the rate of removal of $\mathrm{SiC}$ phase. 
Exposures of the sintered $\mathrm{SiC}$ materials to the endothermic gas resulted in generally more complex reaction kinetics (figures 14 and 15) compared to that observed in the nitrogenbased gas. At 1 torr in the endothermic gas (figure 14) both sintered materials experienced non-linear weight loss due to simultancous etching and carbon formation, apparently by reaction (2). SEM inspection (figure 16) and Raman spectroscopy indicated that the surfaces were covered with layers of amorphous carbon soot. Removal of the soot using a wire brush and/or by vibrating ultrasonically in water, revealed the presence of discontinuous graphitic carbon strongly bonded to the SiC. As suggested by reaction (2), the source of the carbon was believed to be both from the $\mathrm{SiC}$ and the endothermic gas. Removal of $\mathrm{Si}$ from the $\mathrm{SiC}$ surface was apparently rate limited or partially rate limited by gaseous diffusion through the relatively porous surface carbon. At very long exposure times in a tube furnace ${ }^{3,6}$ the sintered $\mathrm{SiC}$ materials actually gained weight as the rate of deposition was significantly more rapid than the rate of etching.

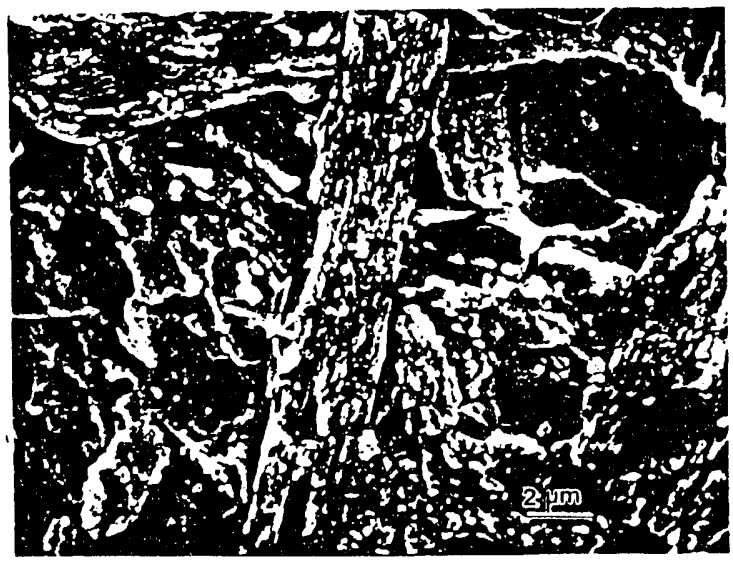

Figure 12. SEM micrograph of the etched surface of the B-doped $\mathrm{SiC}$ exposed to the nitrogen based gas at $1300^{\circ} \mathrm{C}, 1$ torr for $150 \mathrm{~h}$.

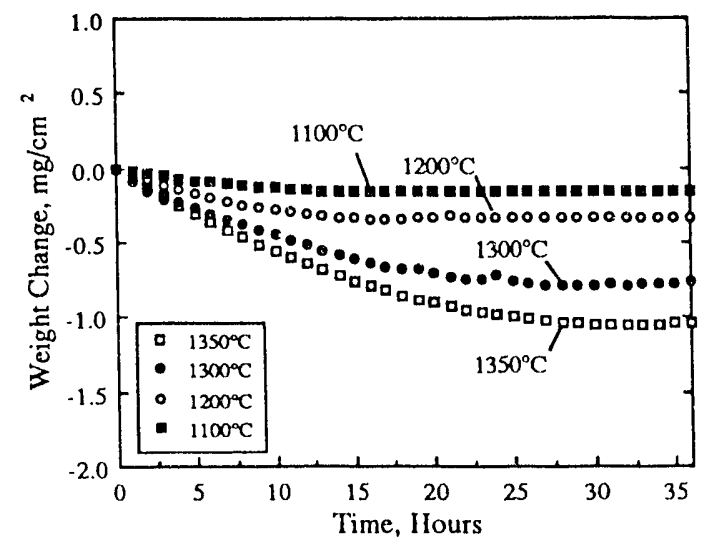

Figure 14. TGA data for the B-doped $\mathrm{SiC}$ exposed to the endothermic gas at 1 torr.

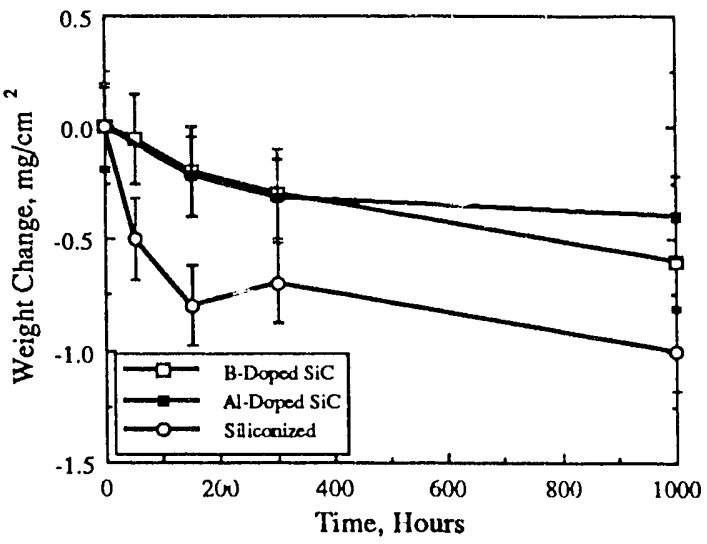

Figure 13. Weight change kinetics of the three $\mathrm{SiC}$ materials exposed to the nitrogenbased gas at $1300^{\circ} \mathrm{C}, 1$ torr for up to $1000 \mathrm{~h}$.

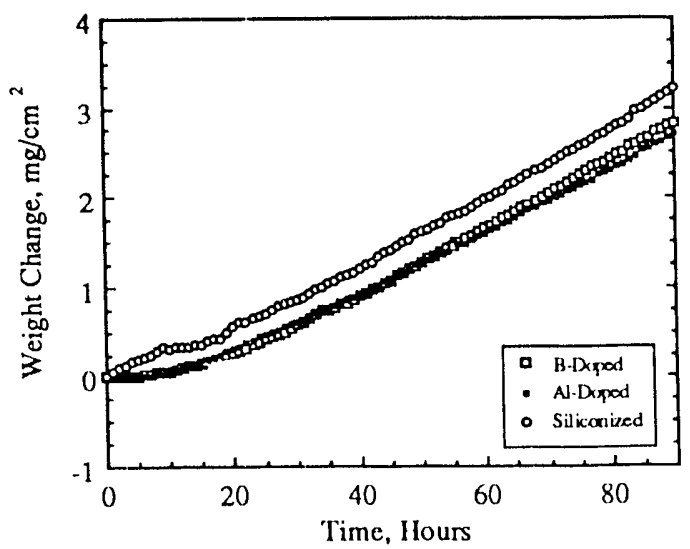

Figure 15. TGA data for the three $\mathrm{SiC}$ materials exposed to the endothermic gas at $1300^{\circ} \mathrm{C}, 1$ torr.

At 740 torr in the endothermic gas all three $\mathrm{SiC}$ materials gained weight relatively rapidly (figure 15) due to the simultancous formation of silica needles and deposition of carbon (figure 17), and, $\mathrm{n}$ the case of the siliconized $\mathrm{SiC}$, the formation of discontinuous calcium 
aluminosilicates. In the case of the sintered materials, the carbon and silica apparently formed by reaction (3). Despite the formation of $\mathrm{SiO}_{2}$, the weight gain profiles of the sintered materials appear similar to that observed during carbon deposition on catalytic surfaces. ${ }^{14}$ The deposition of carbon on a surface is strongly affected by the presence of, for example, catalysts, hydrogen, and cyanogens. ${ }^{14}$ Often the deposition process is characterized by a so-called initial induction period, followed by a period of linear weight gain. The cause of the initial induction period is not clear, but it has been argued that it is caused by either the slow desorption of unreactive adsorbed species from active sites, or may be inherent in the nucleation process itself. ${ }^{14}$

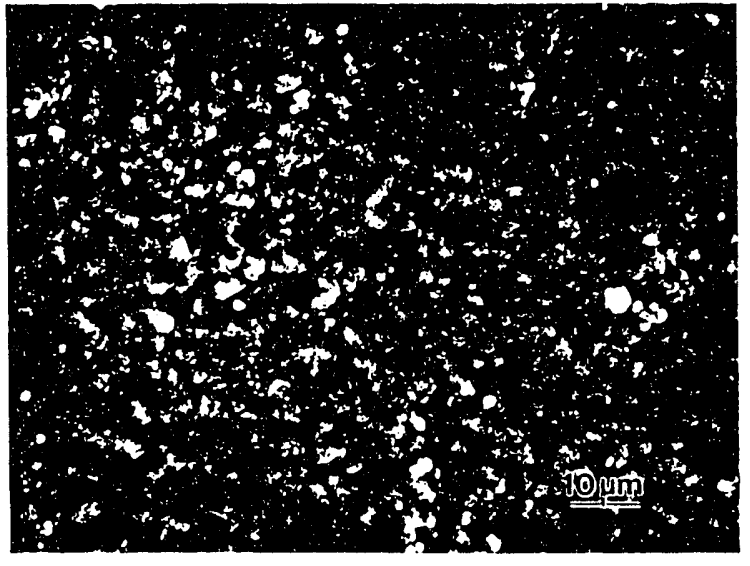

Figure 16. SEM micrograph of the B-doped $\mathrm{SiC}$ surface covered with amorphous carbon after exposure to the endothermic gas at $1300^{\circ} \mathrm{C}, 1$ torr for $100 \mathrm{~h}$.

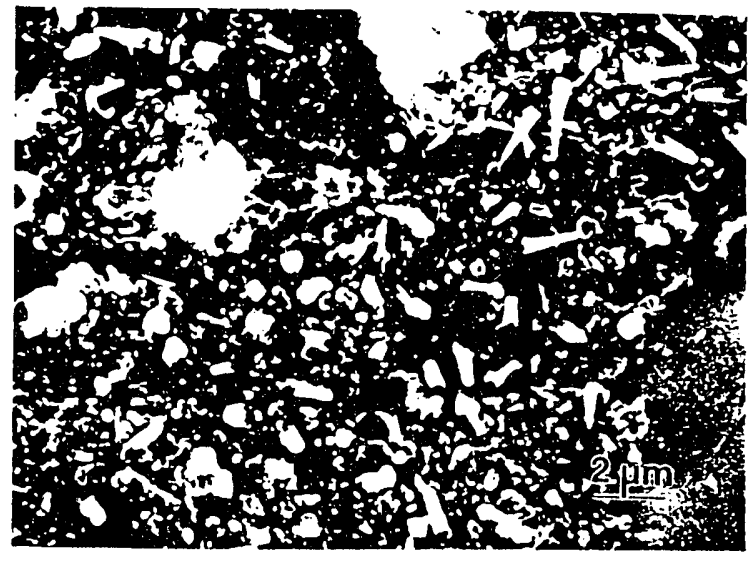

Figure 17. SEM micrograph of the B-doped $\mathrm{SiC}$ surface covered with amorphous carbon and silica needles after exposure to the endothermic gas at $1300^{\circ} \mathrm{C}, 740$ torr, for $90 \mathrm{~h}$.

\subsection{CORROSION OF SINGLE CRYSTAL SiC}

Despite their apparent uniformity (i.e., their lack of grain boundaries and additive phases) both black and light green single crystals of $\mathrm{SiC}$ also experienced selective attack in the $\mathrm{N}_{2}-$ $\mathrm{H}_{2}$ - $\mathrm{CO}$ atmospheres. ${ }^{6}$ Pitting occurred on the surface of the single crystal materials by localized attack near impurities (vanadium in particular) and apparently by attack of crystal defects such as stacking faults and screw dislocations intersecting the $\{0001\}$. Figure 18 shows a $\mathrm{V}$ impurity in the as received black $\mathrm{SiC}$ after exposure to the nitrogen-based gas. As shown in the figure, there was localized attack at the inclusion/SiC interface. If this specimen were exposed for a longer duration, the inclusion would eventually become dislodged from the sample leaving behind a surface pit. Figure 19 shows a relatively large hexagonal etch pit on the surface of the black $\mathrm{SiC}$ that apparently formed due to preferential attack of a screw dislocation. Etch pits were typicaliy hexagonal or distorted hexagonal in shape, owing to the $3 \mathrm{~m}$ and $6 \mathrm{~m}$ symmetry of the hexagona and rhombohedral polytypes of the $\mathrm{SiC}$. It is interesting to note that the hexagonal etch pits tended to grow laterally with exposure time, but tended not to become significantly deeper after $\approx 100 \mathrm{~h}$ of exposure, indicating that the crystal etched more rapidly in the $<0001>$ directions.

\section{Effects of Corrosion on Mechanical Properties and Dominant Flaw Populations}

In the discussion above a number of mechanisms of corrosion and selective attack were identified. Of course, we are concerned with how these processes affect mechanical properties and long term durability. Figures 20 and 21 show the time dependence of strength of all three $\mathrm{SiC}$ materials exposed to the endothermic gas at $1300^{\circ} \mathrm{C}, 1$ and 740 
torr, respectively. (Compare these figures to figures 6,14-17.) Note that the numbers next to the data points represent the number of failures from surface pits per total number of specimens tested. At 1 torr (figure 20), all three materials lost a significant amount of strength during the first $100 \mathrm{~h}$ of corrosion, but between 100 and $300 \mathrm{~h}$ there was no statistically significant decrease in strength. This non-linear behavior has significant engineering implications: if it is known that the strength of a material asymptotically approaches a constant value then a system can be designed to operate below that stress state.

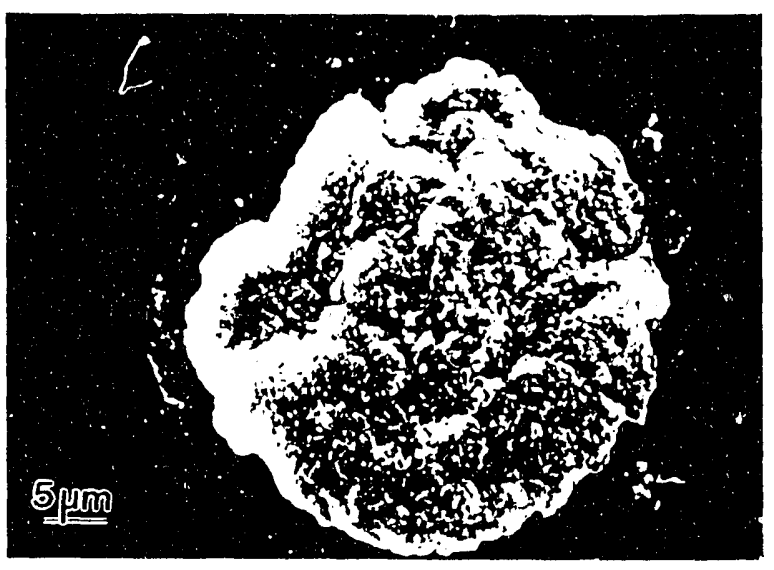

Figure 18. A vanadium-rich inclusion on the surface of black single crystal SiC showing localized attack at the inclusion/SiC interface. (nitrogen-based gas, $1300^{\circ} \mathrm{C}, 1$ torr, 150 h.)

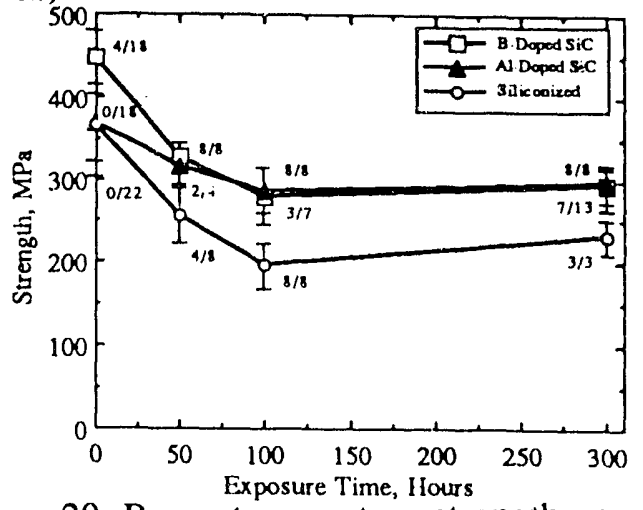

Figure 20. Room temperature strength versus time for the $\mathrm{SiC}$ materials exposed to the endothermic gas at $1300^{\circ} \mathrm{C}, 1$ torr.

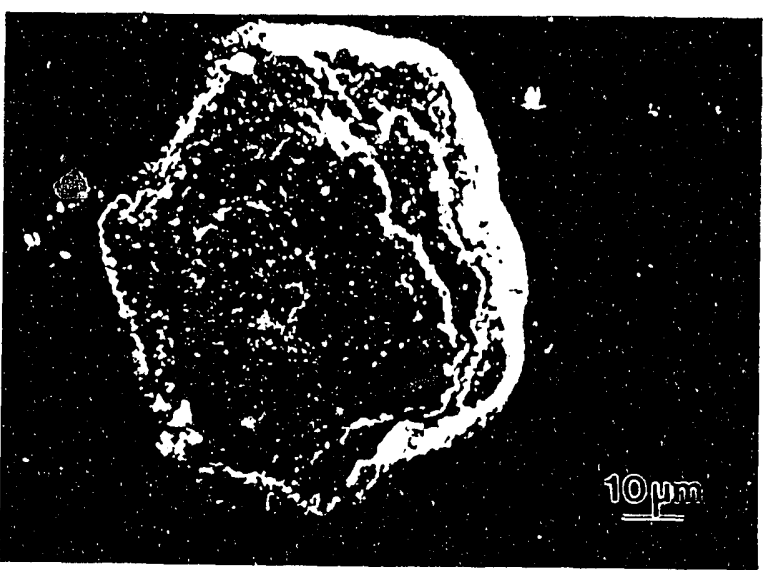

Figure 19. A large hexagonal etcn pit on the surface of black single crystal SiC apparently caused by preferential attack of a screw dislocation. (nitrogen-based gas, at $1300^{\circ} \mathrm{C}, 1$ torr, $1000 \mathrm{~h}$.)

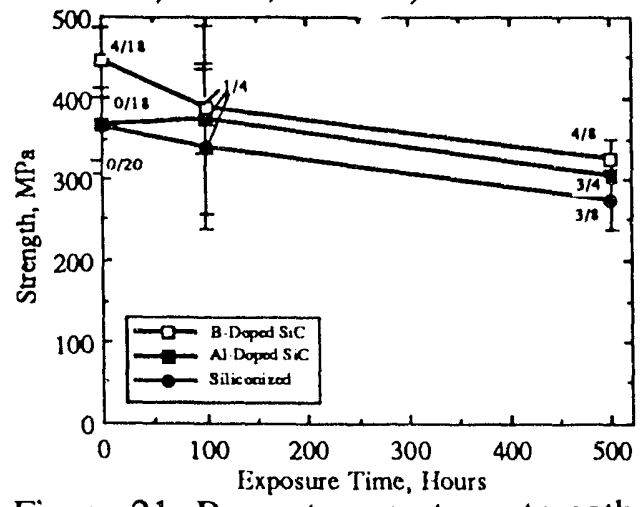

Figure 21. Room temperature strength versus time for the $\mathrm{SiC}$ materials exposed to the endothermic gas at $1300^{\circ} \mathrm{C}, 740$ torr.

The primary cause of failure in corroded specimens was surface, and in the case of the siliconized SiC, internal pits.4,6 Numerous efforts were made to identify the specific mechanisms of pit initiation and growth. In the case of the siliconized SiC, the primary cause of pitting was the removal of Si matrix phase, as shown in figure 22, or impurity sinks as discussed above. In the case of the sintered materials, we were able to directly determine that pitting was at least associated attack of grain boundaries and localized attack near regions containing transition metal impurities. Figure 23 shows a pit on the surface of the Al-doped material where one can see localized attack of grain boundaries and individual 
grains. At the upper region of the pit there was a nickel-rich impurity (shown by arrow). Although we were never able to directly observe the effects of nickel on pitting, numerous pits were found to have similar regions. As discussed elsewhere, 4,6 we also directly observed pit formation at Ti-rich inclusions on the surface of the $\mathrm{Al}$-doped $\mathrm{SiC}$, and on one occasion we observed failure in the B-doped material at a region rich in $\mathrm{Fe}$.

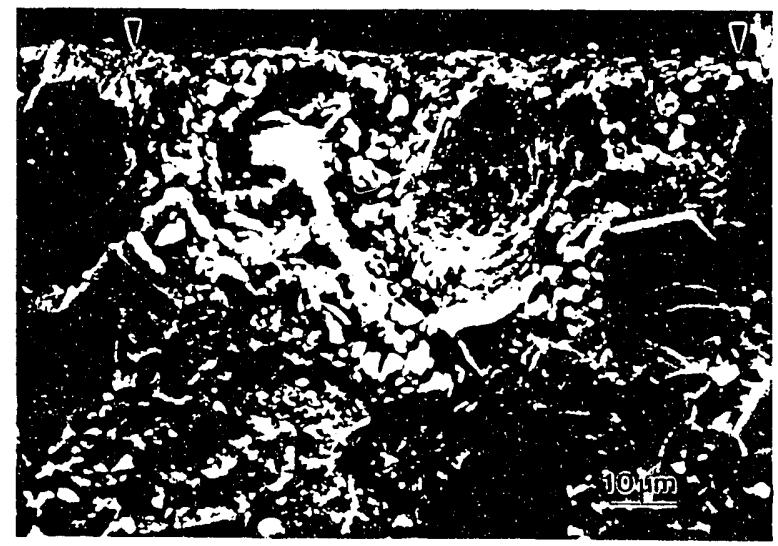

Figure 22. Corrosion pit from which failure occured in the siliconized $\mathrm{SiC}$ at $223.5 \mathrm{MPa}$ $\left(300 \mathrm{~h}, 1\right.$ torr, $1300^{\circ} \mathrm{C}$, endothermic gas).

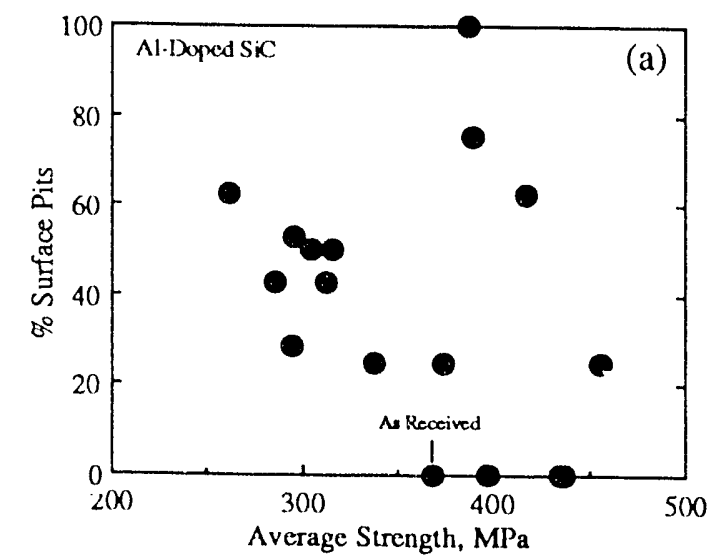

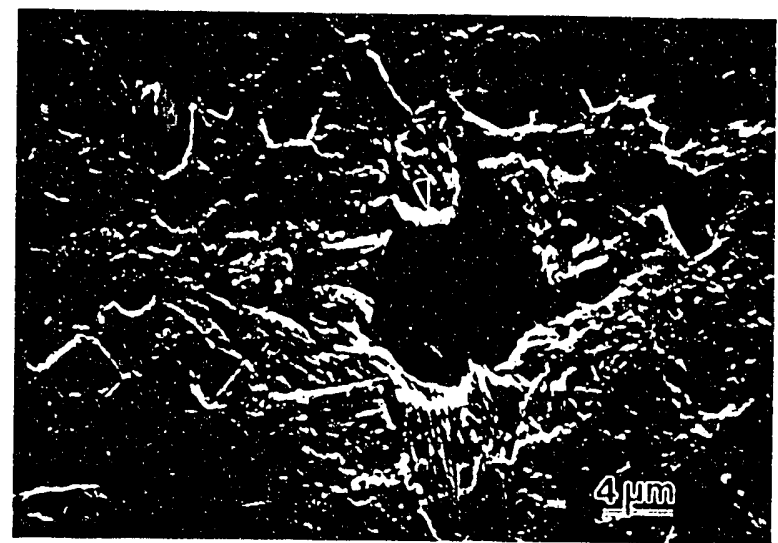

Figure 23. Pit on the surface of the Aldoped SiC showing attack of grains and grain boundaries near a nickel-rich particle (50 h, 1 torr, $1300^{\circ} \mathrm{C}$, endothermic gas).

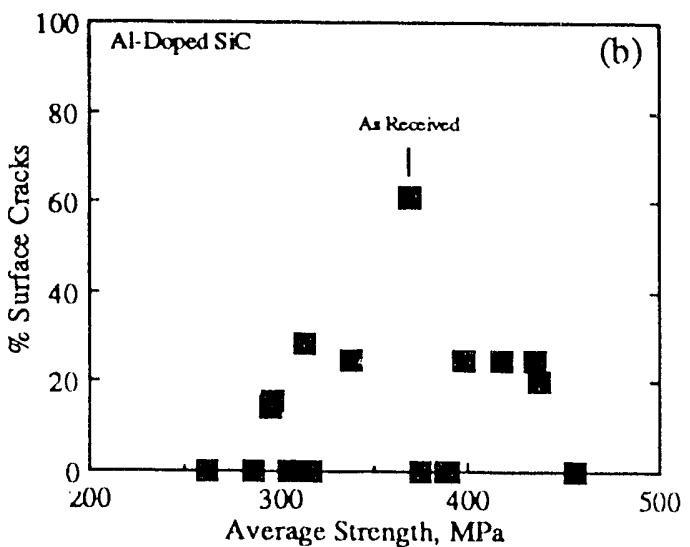

Figure 24. Percentage of failures from (a) surface pits and (b) surface cracks in the Aldoped $\mathrm{SiC}$. Each data point represents a particular long term heat treatment as tabulated elsewhere. ${ }^{4,6}$

Although significant pitting occured in the SiC materials in almost all the test enviroments, in some cases an increase in strength was observed. As illustrated in figure 24 , in the case of the Al-doped $\mathrm{SiC}$, regardless of whether the average strength increase or decreased during corrosion, there was an increase in the percentage of failures from surface pits and a corresponding decrease in the number of failures from surface cracks. Microstructural studies indicateu that crack healing was occuring under some conditions. This was particularly evident in the case of the Al-doped SiC. Studies of indentation cracks before and after corrosion (figure 25 ) showed the cracks healed under certain conditions. ${ }^{4,6}$ Fractography of the Al-doped SiC showed that some specimens failed from what appeared to be surface cracks partially healed by titanium aluminosilicate phases such as that shown in 
figure 26. Although impurities appeared to play a role in the crack healing process, we proposed 4,6 that cracks may also heal in low oxygen partial pressure environments due purely to their surface energy as described by the well known Kelvin equation:

$$
\ln \left(\frac{\mathrm{p}}{\mathrm{p}_{\mathrm{o}}}\right) \approx\left(\frac{2 \gamma \Omega}{\mathrm{rRT}}\right)
$$

where $\gamma$ is the surface energy of the material, $\Omega$ is the molar volume, $\mathrm{r}$ is the radius of curvature (a negative number for a crack tip), and RT has its usual meaning. The term $p_{o}$ represents the equilibrium vapor pressure of gaseous species above a plane surface and $p$ represents the equilibrium pressure above a curved surface. Since the molar volume of SiC equals $18.39 \mathrm{cc} / \mathrm{mol}$ and assuming an average surface energy for polycrystalline $\mathrm{SiC}$ of $\approx 2000 \mathrm{~mJ} / \mathrm{m}^{2}$, the ratio $\mathrm{p} / \mathrm{p}_{\mathrm{o}}$ may be calculated for any crack tip radii using equation 6 . For example, for an atomically sharp crack $(r \approx 5 \AA)$ the drop in the equilibrium vapor pressure from a flat surface to a crack tip would be approximately five orders of magnitude implying a large driving force for vaporization-condensation (or surface diffusion) from the surface of the $\mathrm{SiC}$ materials to sharp crack tips during gas phase etching. Please see other references for a more detailed discussion of crack healing. ${ }^{4,6}$

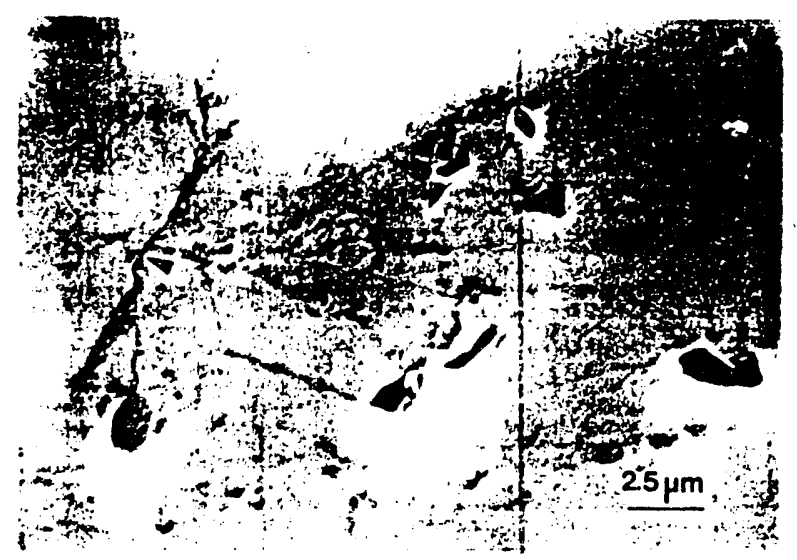

Figure 25. Healed indentation crack on a polished surface of the Al-doped $\mathrm{SiC}(24 \mathrm{~h}$, 1 torr, $1350^{\circ} \mathrm{C}$, nitrogen-based gas).

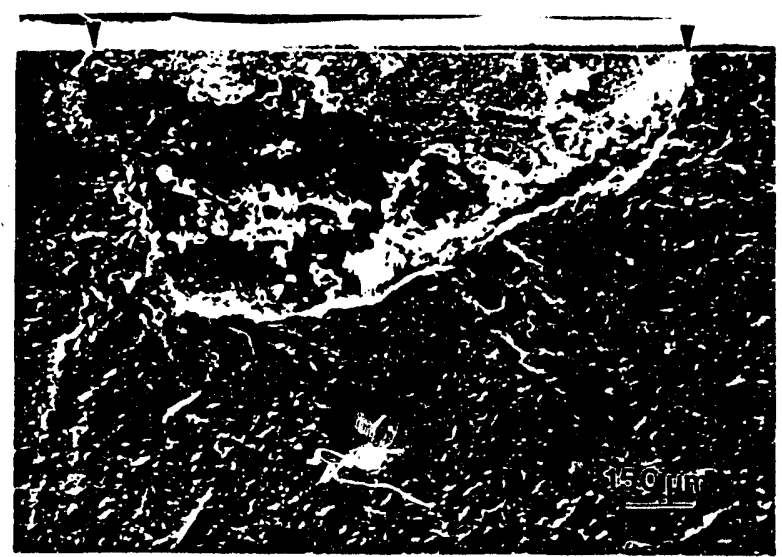

Figure 25. Failure origin in the Al-doped $\mathrm{SiC}$ showing surface crack partially healed by a titanium aluminosilicate phase (205.9 $\mathrm{MPa}$, $100 \mathrm{~h}, 740 \mathrm{torr}, 1200^{\circ} \mathrm{C}$, nitrogen-based gas).

\section{Concludiı.g Remarks}

In $\mathrm{N}_{2}-\mathrm{H}_{2}$-CO heat treatment gases, etching, pitting, and the simultaneous formation of non-protective or semi-protective condensed phases was experimentally observed. However, in the particular atmospheres studied, the rates of attack were relatively slow and the severity of pits tends not to increase significantly beyond a certain period of heat treatment time $(<100$ hours $)$ as evidenced by time-dependent strength studies. The results of kinetic studies and mechanical properties testing indicate that the long term durability of SiC materials should be relatively good in $\mathrm{N}_{2}-\mathrm{H}_{2}-\mathrm{CO}$ heat treatment gases at ten:peratures up to .approximately $1300^{\circ} \mathrm{C}$ providing the retained strength after short term expos:'re is adequate for the particular stress state.

A full understanding of the kinetics of material degradation in low $\mathrm{pC}_{2}$ environments requires an understanding of the mechanisms of selective attack, in particular, processes that lead to pitting. In this study we identified several sites or mechanisms for pit formation including rapid attack of a second phase (Si), grain boundaries, transition metal impurities, 
and crystalline defects. However, it is unlikely that these are the only preferred sites for pit formation, and it could not be concluded from these studies that all of these sites actually lead to flaws more severe that those already present in the material, although certainly some of these mechanisms did lead to strength limiting flaws. Thus, further research is still needed in this area.

\section{Acknowledgment}

This research was funded by the Gas Research Institute, Chicago, IL, USA under contract no. 5084-238-1302.

\section{References}

1. ASM Committee on Furnace Atmospheres, "Fumace Atmospheres,"; pp. 389-416 in Me!als Handbook, 9th ed., Vol. 4. American Society of Metals, Metals Park, OH, 1981.

2. N. S. Jacobson, "Corrosion of Silicon-Based Ceramics in Combustion Environments," J. Am. Ceram. Soc., 76 [1] 3-28 (1993).

3. D. P. Butt, R. E. Tressler, and K. E. Spear, "Corrosion of SiC Materials in $\mathrm{N}_{2}-\mathrm{H}_{2}$-CO Gaseous Environments: I, Thermodynamics and Kinetics of Reactions," J. Am. Ceram. Soc., 75 [12] 3257-3267 (1992).

4. D. P. Butt, R. E. Tressler, and K. E. Spear, "Corrosion of SiC Materials in $\mathrm{N}_{2}-\mathrm{H}_{2}-\mathrm{CO}$ Gascous Environments: II, Durability and Mecharical Properties," J. Am. Ceram. Soc., 75 [12] 3268-3277 (1992).

5. D. P. Butt, R. E. Tressler, and K. E. Spear, "Corrosion of Silicon Carbide Materials in Metallurgical Heatİ iatment Environments," Am. Ceram. Soc. Bull., 71 [11] 1683-1690 (1992).

6. D. P. Butt, "Thermodynamics, Kinetics, and Durability of Silicon Carbide Materials in Nitrogen-HydrogenCarbon Monoxide Gaseous Environments at Elevated Temperatures"; Ph.D. Thesis. The Pennsylvania State University, University Park, PA, 1991.

7. G. Eriksson, "Thermodynamic Studies of High Temperature Equilibria," Chemica Scripta, 8, 100-103 (1975).

8. JANAF Thermochemical Tables, 3rd Ed., M.W. Chase, Jr., C.A. Davies, J.R. Downey, Jr., D.J. Frurip, R.A. McDonald, and A.N. Syverud, Editors, Am. Chem. Soc. and the Am. Institute of Phys. for the NBS, Volume 14, 1985.

9. Personal correspondence with M.W. Chase, NIST, Gaithersburg, MD: corrections to erroneous data for CN and $\mathrm{C}_{2} \mathrm{H}_{2}$ in reference 8 .

10. I. Barin and O. Knacke, Thermochemical Properties of Inorganic Substances, Springer-Verlag, Germany 1973.

11. M. B. Fegley, Jr., "The Thermodynamic Properties of Silicon Oxynitride," J. Am. Ceram. Soc., 64 [9] C124-126 (1981).

12. D. R. Stull, E. F. Westrum, Jr., and G. C. Sinke, The Chemical Thermodynamics of Organic Compounds, John Wiley \& Sons, Inc., New York, 1969.

13. R. Schmid, "Thermodynamic Analysis of the Melting Equilibria in the Iron-Silicon System," CALPIIAD: Comput. Coupling Phase Diagrams Thermochem., 4 [2] 101-108 (1980).

14. P.L. Walker, Jr. and J. M. Thomas, "The Catalyzed Disproportionation of Carbon Monoxide," Carbon, 8 [1] 103-104 (1969). 

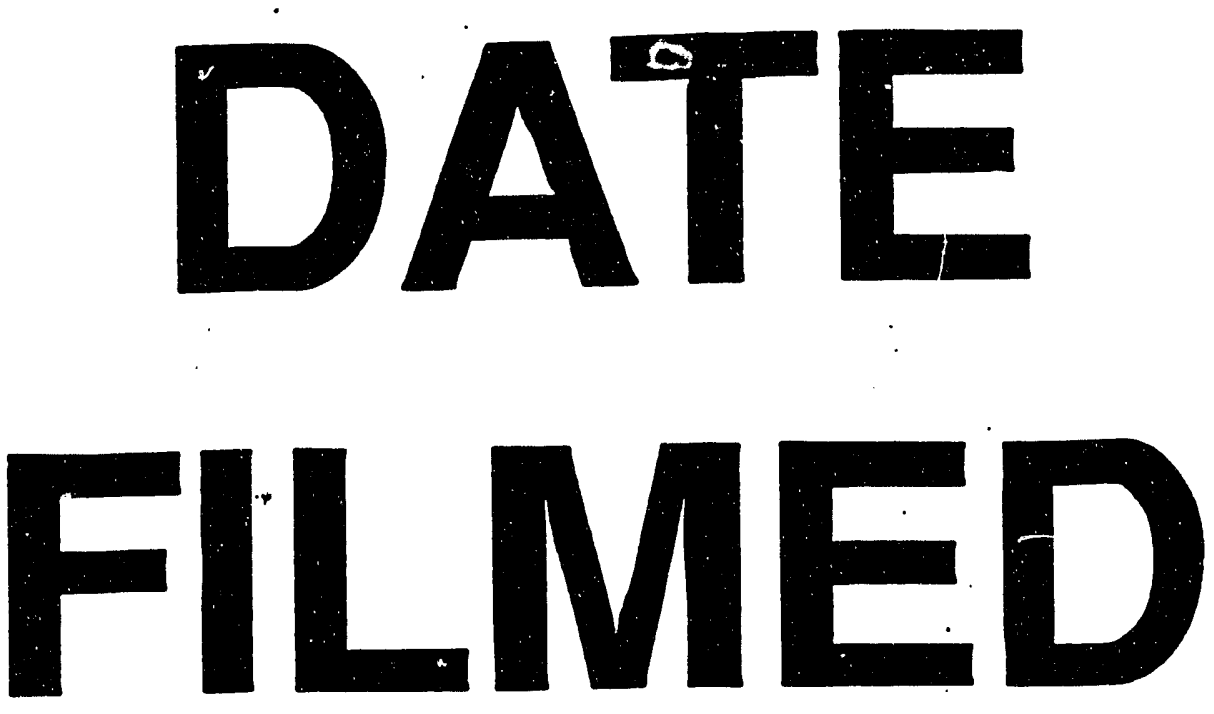

12
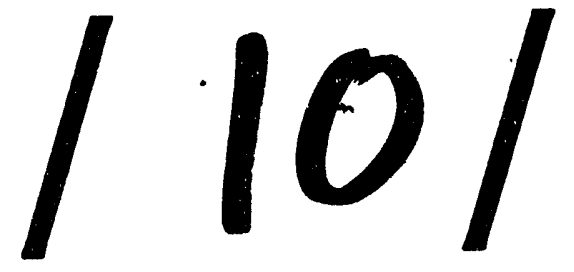

93
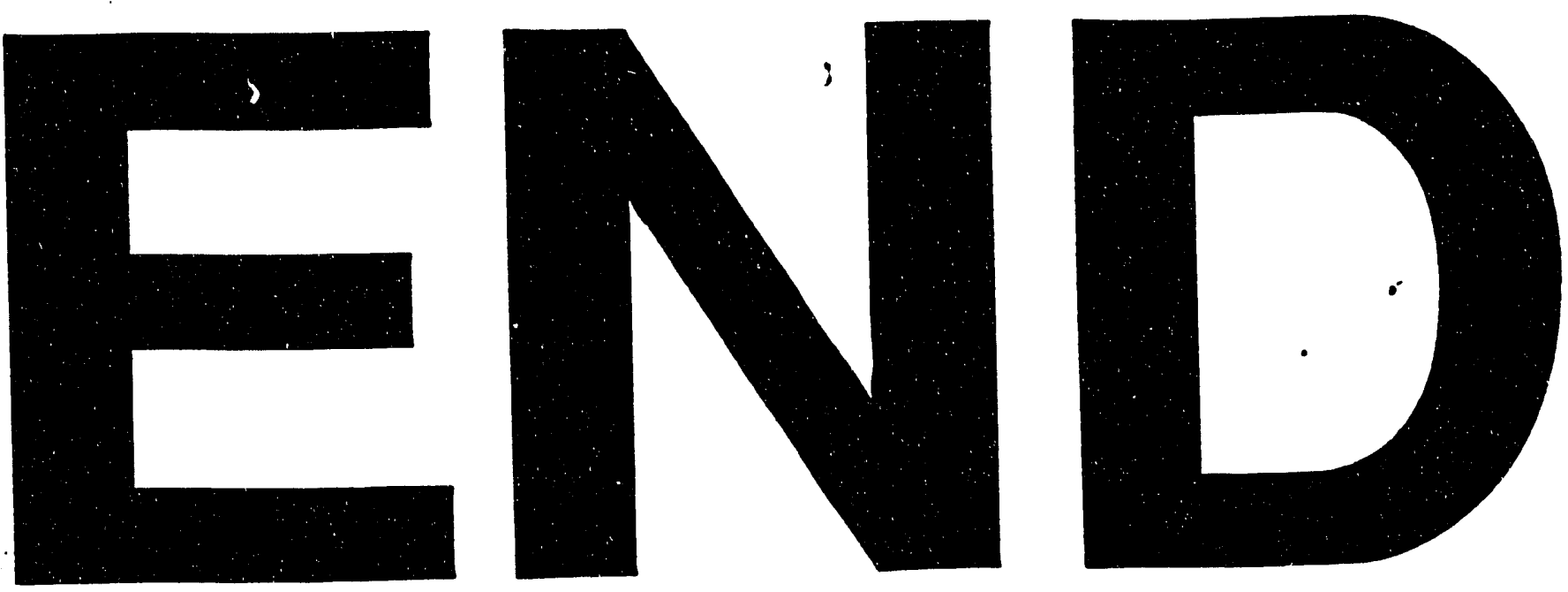
